\title{
MASS SPECTROMETRY OF PERTRIMETHYLSILYL ALDOSYL OLIGOSACCHARIDES
}

\author{
J. P. Kameruing and J. F. G. Vliegenthart \\ Laboratory of Organic Chemistry, University of Utrecht, The Netherlands \\ J. VINK and J. J. DE RIDDER \\ Laboratory of Analytical Chemistry, University of Utrecht. The Netherlands
}

(Received in the UK 14 April 1971; Accepted for publication 20 April 1971)

\begin{abstract}
The mass spectra of 18 trimethylsilyl disaccharides containing only aldohexoses, connected via all possible linkages $(1 \rightarrow 1)$ to $(1 \rightarrow 6)$, were compared. These spectra could be divided into three main groups: $(1 \rightarrow 1)$ disaccharides, $(1 \rightarrow 2),(1 \rightarrow 3),(1 \rightarrow 4)$ disaccharides and $(1 \rightarrow 5),(1 \rightarrow 6)$ disaccharides. $(\mathrm{l} \rightarrow 2),(1 \rightarrow 3)$ and $(1 \rightarrow 4)$ disaccharides could be distinguished on the basis of two ratios of peak intensities. $(1 \rightarrow 5)$ and $(1 \rightarrow 6)$ disaccharides could not be distinguished. Also, the mass spectra of 4 trimethylsilyl trisaccharides built up from aldohexoses only were recorded. The spectra of three aldopentose containing disaccharides showed that the monosaceharide sequence as well as the position of the glycosidic link could be determined.
\end{abstract}

\section{INTRODUCTION}

AS PART of a study on the structure determination of carbohydrate containing biopolymers, we investigated the applicability of mass spectrometry to the structure elucidation of oligosaccharide fragments.

The following parameters define the structure of an oligo- or polysaccharide: (i) nature and number of the constituting monosaccharides, (ii) sequence of these units. (iii) ring size of the monosaccharides, (iv) position of the glycosidic linkages, (v) configuration of these bonds, (vi) configuration of the anomeric carbon atom of the reducing unit. Several approaches have been made to capture some of these parameters by mass spectrometric analysis of oligosaccharide derivatives. The number of monomers in an oligosaccharide can be derived from the mass spectrum. Further, it has been shown that in several oligosaccharides built up from aldohexoses the position of the glycosidic. linkages can be established. Chizhov et al. ${ }^{1}$ demonstrated that disaccharides with $(1 \rightarrow 2),(1 \rightarrow 4)$ and $(1 \rightarrow 6)$ links can be distinguished from each other by mass spectrometry of the methyl ethers. Kochetkov et al ${ }^{2,3}$ used trimethylsilyl ethers of oligosaccharides and could determine for some di- and trisaccharides the position of the glycosidic bonds in cases of $(1 \rightarrow 2),(1 \rightarrow 3),(1 \rightarrow 4)$ and $(1 \rightarrow 6)$ connexion. Kärkkäinen investigated trimethylsilyl ethers ${ }^{4}$ and methyl ethers ${ }^{5}$ of disaccharide alditols and was capable of establishing $(1 \rightarrow 3),(1 \rightarrow 4)$ and $(1 \rightarrow 6)$ links. Johnson et al. ${ }^{6}$ described the mass spectra of a few 1-phenylflavazole peracetates of di- to pentasaccharides and could discriminate between $(1 \rightarrow 4)$ and $(1 \rightarrow 6)$ glycosidic linkages. Recently, Kärkkäinen published a study concerning the mass spectrometry of permethyl trisaccharides ${ }^{7}$ and trisaccharide alditols. ${ }^{8}$ In some disaccharides, containing units with different molecular weight, the position of the glycosidic link as well as the sequence of the monomers could be established. ${ }^{3-5}$ Vink et al. ${ }^{9}$ showed that some stereoisomeric aldohexosyl-aldohexoses could be 
distinguished by mass spectrometry of their trimethylsilyl derivatives; the configuration of the anomeric $\mathrm{C}$-atom of the reducing unit exhibited a great influence on the fragmentation pattern.

None of the investigations concerning the estimation of the glycosidic link included all possible positions of these bonds in disaccharides. In order to develop a more generally applicable scheme, in which all link possibilities are considered. we studied the mass spectra of the whole series of aldohexosyl- $(1 \rightarrow \mathrm{x})$-aldohexoses with $x=1$. $2,3,4.5$ or 6 . Furthermore we investigated how far such a scheme can be extrapolated to disaccharides containing aldopentoses and to aldohexosyl trisaccharides. For this work trimethylsilyl (TMS) derivatives were chosen, because besides their high volatility and suitability for gas-liquid chromatography (Haverkamp et al. ${ }^{10}$ and Bhatti et al. ${ }^{11}$ ) they also lend themselves to NMR spectroscopy for the determination of the configuration of the glycosidic links (Kamerling et al. ${ }^{12}$ ).

\section{RESULTS}

Disaccharides consisting of aldohexoses

Mass spectra of TMS ethers of the disaccharides I to XVIII were recorded (Table 1). The molecular ion at $m / e 918$ was not detectable in the spectra of I, II, III, VII and VIII; in these cases the first detectable fragment ion was $m / e 903\left(\mathrm{M}^{+}-{ }^{\circ} \mathrm{CH}_{3}\right)$. In

TABLE 1. LIST OF STUDIED OLIGOSACCHARIDES

\begin{tabular}{|c|c|}
\hline I & $\alpha$-D-glucopyranosyl- $(1 \rightarrow 1)-\alpha$-D-glucopyranoside ( $=\alpha, \alpha$-trehalose $)^{\bullet}$ \\
\hline II & $\beta$-D-glucopyranosyl-(1 $\rightarrow 1)-\beta$-D-glucopyranoside ( $=\beta, \beta$-trehalose) \\
\hline III & $\alpha$-D-galactopyranosyl- $(1 \rightarrow 1)-\alpha$-D-galactopyranoside $(=\alpha, \alpha$-galactotrehalose $)$ \\
\hline IV & B-D-glucopyranosyl-(1 $\rightarrow$ 2)-D-glucose (= sophorose) \\
\hline v & $\alpha$-D-glucopyranosyl-(1 $\rightarrow$ 2)-D-glucose (= kojibiose) \\
\hline VI & $\beta$-D-glucopyranosyl- $(1 \rightarrow 3)$-D-glucose (= laminaribiose) \\
\hline VII & $\alpha$-D-mannopyranosyl- $(1 \rightarrow 3)$-D-mannose \\
\hline VIII & $\alpha$-D-glucopyranosyl-(1 $\rightarrow$ 4)-D-glucopyranose $(=\text { maltose })^{\circ}$ \\
\hline IX & B-D-glucopyranosyl- $(1 \rightarrow 4)$-D-glucopyranose $(=\text { cellobiose })^{a}$ \\
\hline $\mathbf{x}$ & B-D-galactopyranosyl-(1 $\rightarrow$ 4)-D-glucopyranose (= lactose) \\
\hline $\mathbf{X I}$ & $\beta$-D-galactopyranosyl- $(1 \rightarrow 4)$-D-altropyranose (= neolactose) \\
\hline XII & Q-D-mannopyranosyl- $(1 \rightarrow 4)$-D-mannopyranose ( = mannobiose) \\
\hline XIII & $\alpha$-D-glucopyranosyl-(1 $\rightarrow$ 5)-D-glucofuranose (= maniocose) \\
\hline XIV & B-D-glucopyranosyl-(1 $\rightarrow$ 6)-D-glucose ( = gentiobiose $)^{a}$ \\
\hline$x V$ & $\alpha$-D-glucopyranosyl-(1 $\rightarrow$ 6)-D-glucose $(=\text { isomaltose })^{\alpha}$ \\
\hline XVI & $\alpha$-D-galactopyranosyl- $(1 \rightarrow 6)-D$-glucose (= melibiose) \\
\hline XVII & $\alpha$-D-mannopyranosyl-(1 $\rightarrow 6$-D-glucose \\
\hline XVIII & B-D-galactopyranosyl- $(1 \rightarrow 6)$-D-galactose \\
\hline XIX & $\beta$-D-glucopyranosyl- $(1 \rightarrow 2)$-L-arabinose \\
\hline $\mathbf{X X}$ & B-D-galactopyranosyl- $\{1 \rightarrow 3\}$-D-arabinose \\
\hline XXI & $\beta$-D-xylopyranosyi- $(1 \rightarrow 6)$-D-glucose (= primeverose) \\
\hline XXII & $\alpha$-D-glucopyranosyl-( $(\rightarrow 4)-\alpha$-D-glucopyranosyl- $(1 \rightarrow 4)$-D-glucopyranose ( \\
\hline XXIII & $\beta$-D-glucopyranosyl-(1 $\rightarrow 4)-\beta$-D-glucopyranosyl-(1 $\rightarrow$ 4)-D-glucopyranose (= cellotriose) \\
\hline XXIV & $\alpha$-D-glucopyranosyl- $(1 \rightarrow 6)-\alpha$-D-glucopyranosyl- $(1 \rightarrow 6)-D-$-glucose $\left(={\text { isomaltotriose })^{b}}^{b}\right.$ \\
\hline XXV & $\alpha$-D-glucopyranosyl-(1 $\rightarrow 6)-\alpha$-D-glucopyranosyl-(1 $\rightarrow 4)$-D-glucopyranose (= panose) $)^{x}$ \\
\hline
\end{tabular}

- J. T. Baker Chemicals N.V.

- Pierce Chemical Company

- EGA-Chemie KG 
TABLE 2. EXPLANATION OF SOME IMPORTANT ERAGMENT IONS, PRESENT IN MOST OF THE SPECTRA OF TMSALDOHEXOSYL-ALDOHEXOSES

\begin{tabular}{|c|c|c|}
\hline$m / e$ & $\begin{array}{c}\text { measured } \\
\text { britoformula }\end{array}$ & fragment \\
\hline 918 & & $\mathbf{M}^{+}$ \\
\hline 903 & & $\mathrm{M}^{+}-\mathrm{CH}_{3}$ \\
\hline 828 & & $\mathrm{M}^{+}-\mathrm{TMSOH}$ \\
\hline 815 & & $\mathrm{M}^{+}-\mathrm{CH}_{2}$ OTMS \\
\hline 813 & & $903^{+}-$TMSOH \\
\hline 771 & $\mathrm{C}_{30} \mathrm{H}_{71} \mathrm{O}_{9} \mathrm{Si}_{7}$ & $903^{+}-\mathrm{TMSOCH}_{2}-\mathrm{CH}=\mathrm{O}$ \\
\hline 739 & & $828^{+}-$OTMS \\
\hline 738 & & $828^{+}-\mathrm{TMSOH}$ \\
\hline 725 & & $815^{+}-\mathrm{TMSOH}$ \\
\hline 723 & & $813^{+}-\mathrm{TMSOH}$ \\
\hline 683 & $\mathrm{C}_{27} \mathrm{H}_{63} \mathrm{O}_{8} \mathrm{Si}_{6}$ & TMSO- $-\mathrm{CH}=\mathrm{C}(\mathrm{OTMS})-\mathrm{CH}=\mathrm{O}-\mathrm{Gl}$ (reducing end) \\
\hline 668 & $\mathrm{C}_{27} \mathrm{H}_{64} \mathrm{O}_{3} \mathrm{Si}_{6}$ & $\mathrm{M}^{+}-\mathrm{TMSOCH}_{2}-\mathrm{CH}=\mathrm{O}-\mathrm{TMSO}-\mathrm{CH}=\mathrm{O}$ \\
\hline 649 & & $739^{+}-\mathrm{TMSOH}$ \\
\hline 633 & & $723^{+}-\mathrm{TMSOH}$ \\
\hline 611 & $\mathrm{C}_{24} \mathrm{H}_{55} \mathrm{O}_{8} \mathrm{Si}_{5}$ & $815^{+}-\mathrm{TMSO}-\mathrm{CH}=\mathrm{CH}-\mathrm{OTMS}$ \\
\hline 595 & $\mathrm{C}_{24} \mathrm{H}_{55} \mathrm{O}_{7} \mathrm{Si}_{5}$ & $\mathrm{Gl}-\mathrm{O}=\mathrm{CH}-\mathrm{CH}=\mathrm{CH}-\mathrm{OTMS}$ \\
\hline 583 & & $\mathrm{Gl}-\mathrm{O}-\mathrm{CH}_{2}-\mathrm{CH}=\stackrel{+}{\mathrm{O}} \mathrm{TMS}(\mathrm{l} \rightarrow 6)$ (non-reducing end) \\
\hline $\begin{array}{l}582 \\
578\end{array}$ & $\begin{array}{l}\mathrm{C}_{23} \mathrm{H}_{54} \mathrm{O}_{7} \mathrm{Si}_{3} \\
\mathrm{C}_{24} \mathrm{H}_{54} \mathrm{O}_{6} \mathrm{Si}_{3}\end{array}$ & $\begin{array}{l}\mathrm{Gl}-\stackrel{+}{\mathrm{O}}=\mathrm{CH}-\mathrm{CH}_{2} \mathrm{OTMS}(1 \rightarrow 5) \text { (non-reducing end) } \\
{[\mathrm{TMSO}-\mathrm{CH}=\mathrm{CH}-\mathrm{O}-\mathrm{Gl}]^{+}} \\
668^{+}-\mathrm{TMSOH}\end{array}$ \\
\hline 569 & $\mathrm{C}_{22} \mathrm{H}_{53} \mathrm{O}_{7} \mathrm{Si}_{5}$ & TMSO $-\mathrm{CH}=\mathrm{O}-\mathrm{Gl}$ (reducing end) \\
\hline 539 & $\mathrm{C}_{21} \mathrm{H}_{31} \mathrm{O}_{6} \mathrm{Si}_{3}$ & $540^{+}-H(\sec t e x t)$ \\
\hline 525 & & $540^{+}-\mathrm{CH}_{3}$ \\
\hline 521 & $\mathrm{C}_{21} \mathrm{H}_{45} \mathrm{O}_{7} \mathrm{Si}_{4}$ & $611^{*}$-TMSOH \\
\hline 467 & $\mathrm{C}_{18} \mathrm{H}_{43} \mathrm{O}_{6} \mathrm{Si}_{4}$ & {$[\mathrm{Gl}-\mathbf{O}]^{+}$} \\
\hline 451 & $\mathrm{C}_{18} \mathrm{H}_{43} \mathrm{O}_{5} \mathrm{Si}_{4}$ & {$[\mathrm{Gl}]^{+}$} \\
\hline 435 & $\mathrm{C}_{17} \mathrm{H}_{39} \mathrm{O}_{5} \mathrm{Si}_{4}$ & $525^{+}-\mathrm{TMSOH}$ \\
\hline 361 & $\mathrm{C}_{15} \mathrm{H}_{33} \mathrm{O}_{4} \mathrm{Si}_{3}$ & $451^{*}-\mathrm{TMSOH}$ \\
\hline 217 & $\mathrm{C}_{9} \mathrm{H}_{21} \mathrm{O}_{2} \mathrm{Si}_{2}$ & TMSO $-\mathrm{CH}=\mathrm{CH}-\stackrel{\top}{\mathrm{C}} \mathrm{H}-\mathrm{OTMS}$ \\
\hline 204 & $\mathrm{C}_{8} \mathrm{H}_{20} \mathrm{O}_{2} \mathrm{Si}_{2}$ & TMSO- $\stackrel{+}{\mathrm{C}} \mathrm{H}-\dot{\mathrm{C}} \mathrm{H}-\mathrm{OTMS}$ \\
\hline 191 & $\mathrm{C}_{7} \mathrm{H}_{19} \mathrm{O}_{2} \mathrm{Si}_{2}$ & $\mathrm{TMSO}-\mathrm{CH}=\mathrm{O} \mathrm{TMS}$ \\
\hline
\end{tabular}

Gl = Glycose unit

general the fragmentations show great similarity, as can be expected for so closely related substances. For the interpretation of a number of fragments, (Table 2), use has been made of the data given by Kochetkov et al. ${ }^{3}$ The characteristic differences in the spectra resulting from variations in the position of the glycosidic bond may become evident from Tables 3 and 4 and from Figs 1-6, which represent the spectra of TMS-glucosyl-glucoses with the intermolecular bond in the positions $(1 \rightarrow 1)$, $(1 \rightarrow 2),(1 \rightarrow 3),(1 \rightarrow 4),(1 \rightarrow 5)$ and $(1 \rightarrow 6)$ respectively.

The spectra of the TMS-aldohexosyl- $(1 \rightarrow 1)$-aldohexoses stand completely apart; by the presence of $m / e 565, \mathrm{~m} / \mathrm{e} 553$ and $\mathrm{m} / \mathrm{e} 540$.

The TMS-disaccharides with $(1 \rightarrow 5)$ or $(1 \rightarrow 6)$ links can be distinguished from 


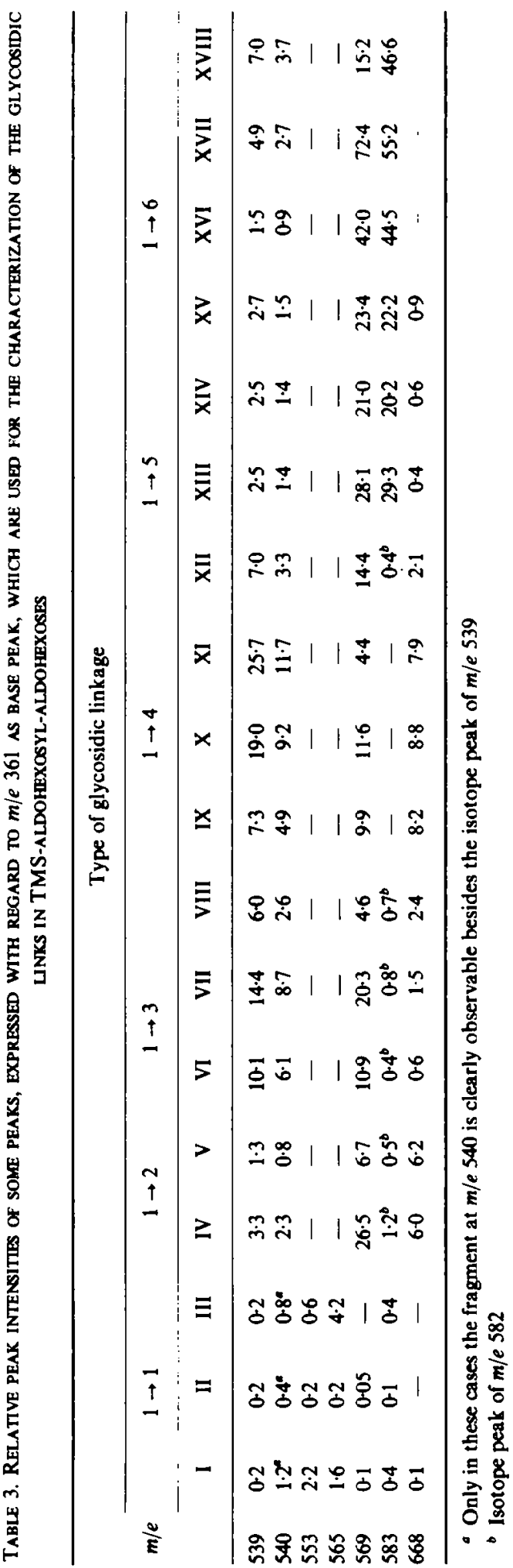




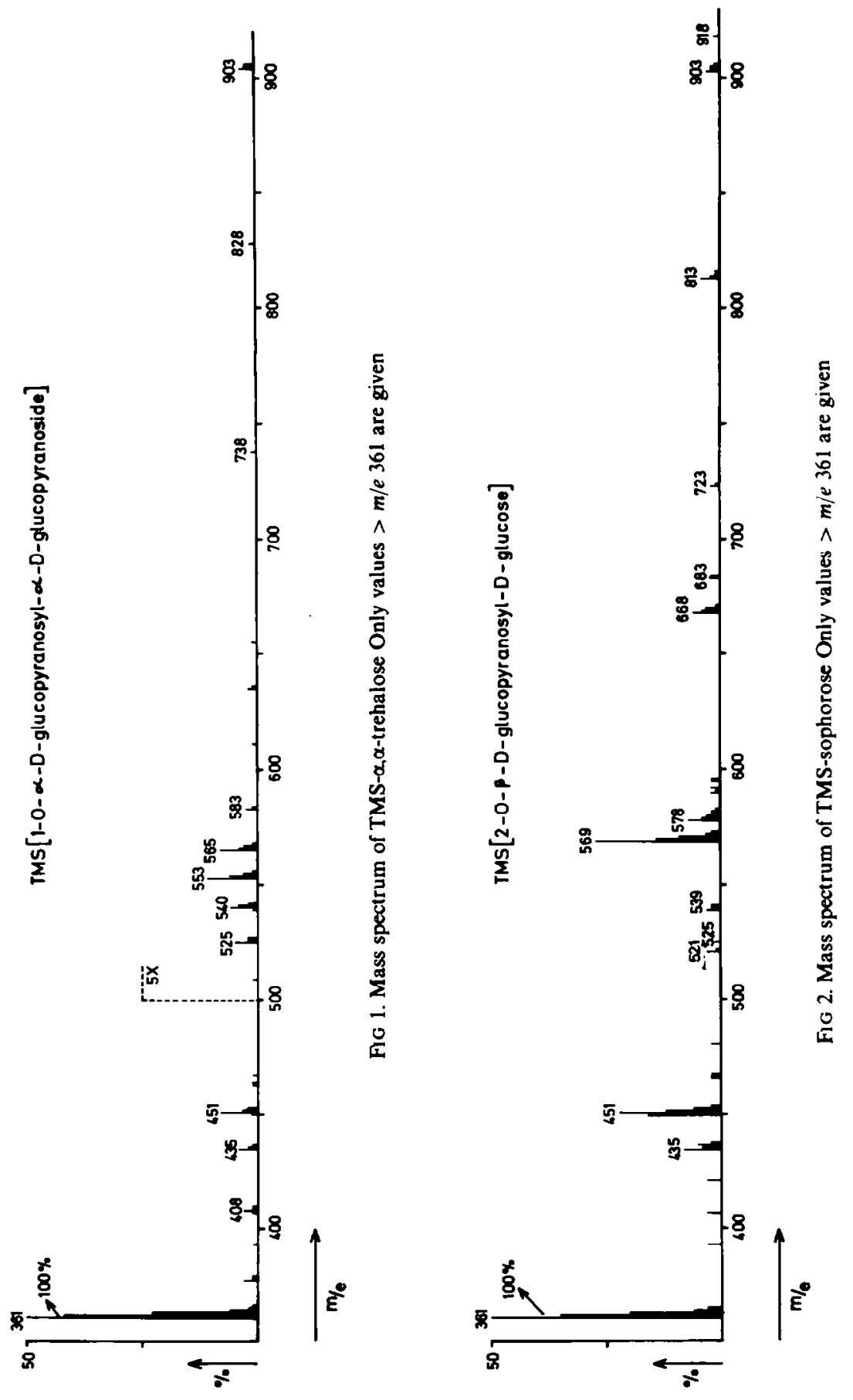



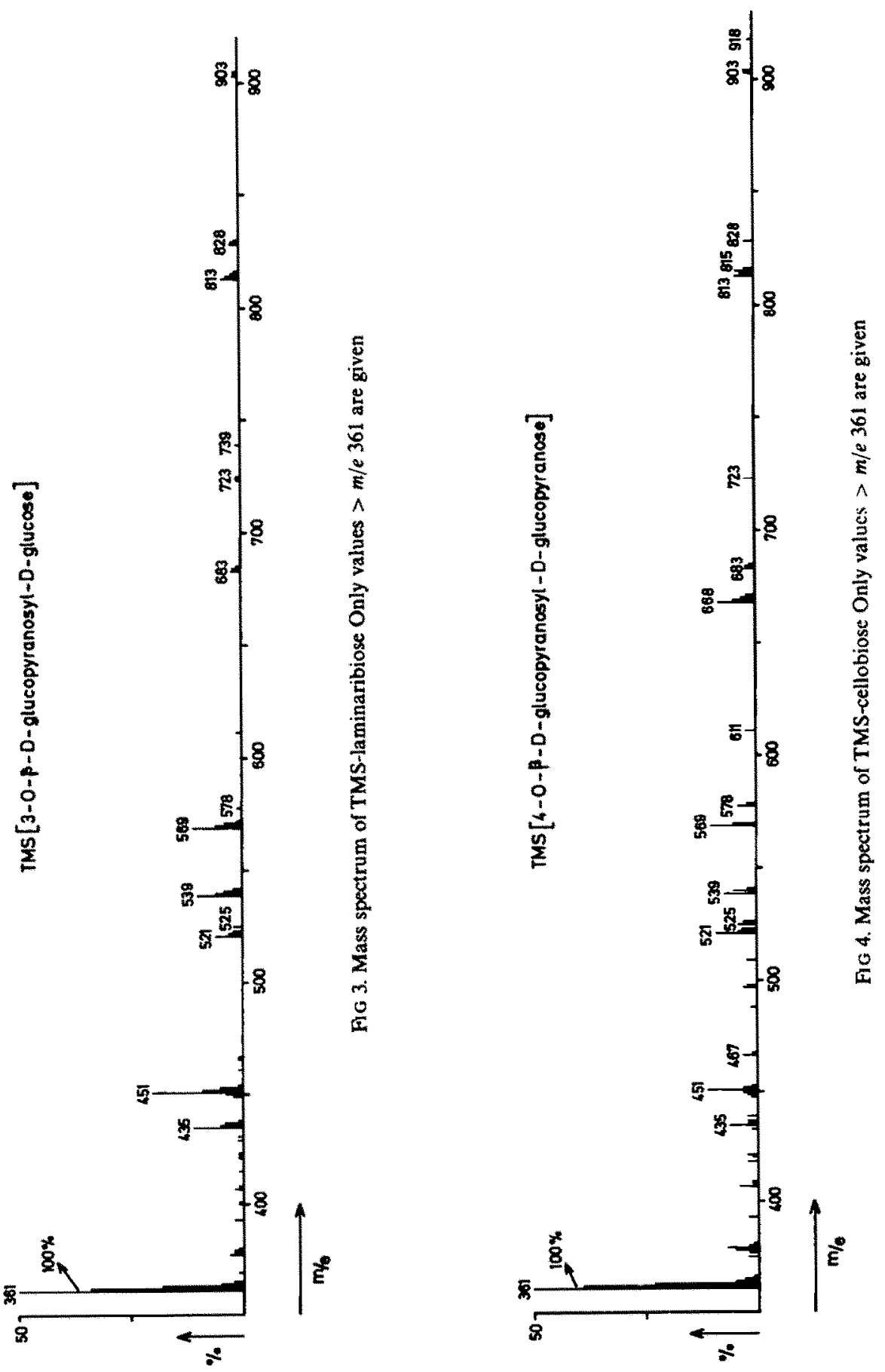

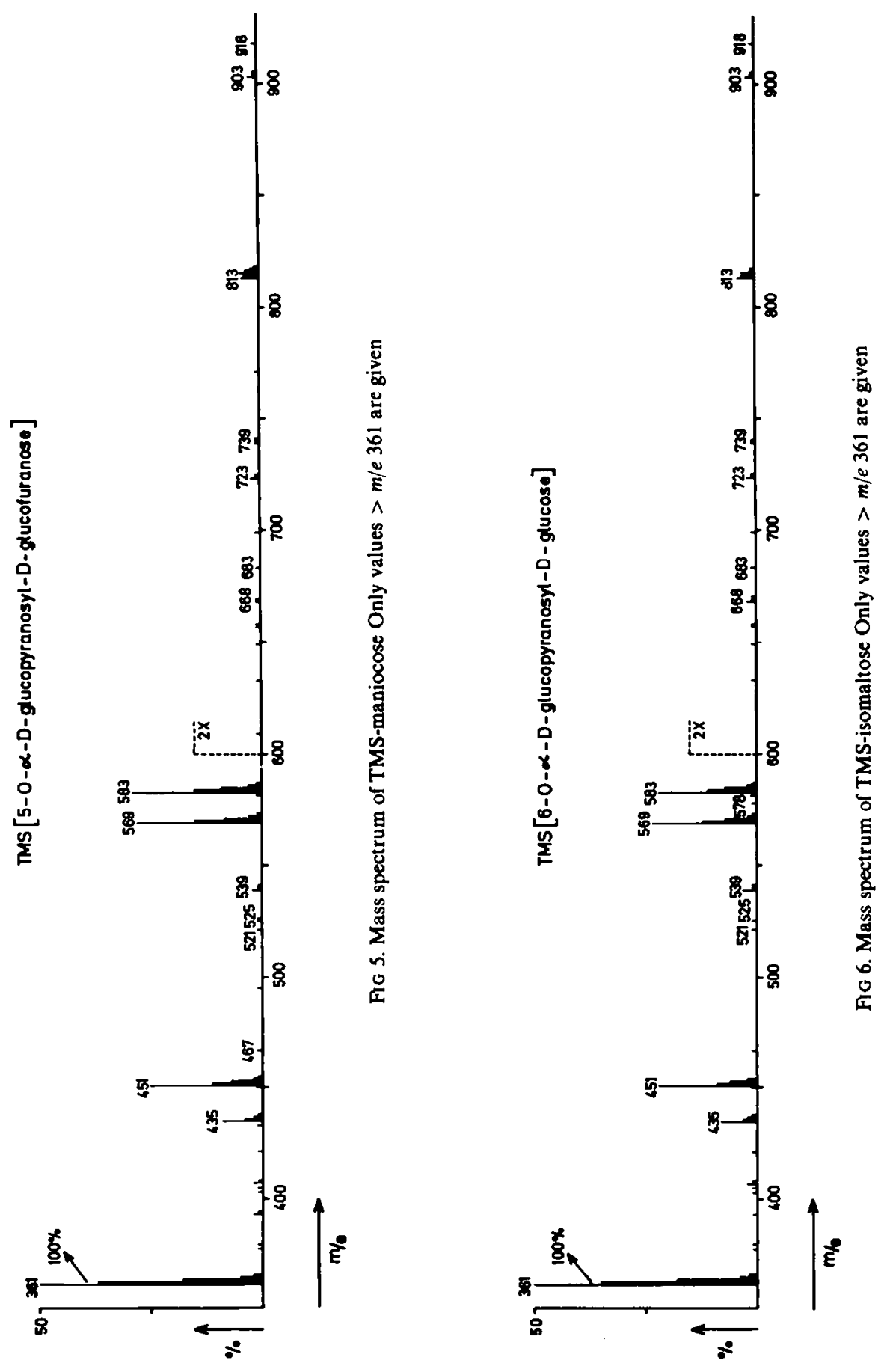
the remaining disaccharides by the occurrence of a very strong peak at $m / e 583$. It was impossible to differentiate between these two types of bonding.

The mass spectra of the TMS-disaccharides with $(1 \rightarrow 2),(1 \rightarrow 3)$ and $(1 \rightarrow 4)$ connexions are very similar. Nevertheless it was possible to correlate the type of bonding with the ratios of the intensities of the peaks at $m / e 569$ and $m / e 539$ (569/539) and at $m / e 569$ and $m / e 668(569 / 668)$ (Table 4).

\begin{tabular}{|c|c|c|}
\hline & $569 / 539$ & $569 / 668$ \\
\hline $1 \rightarrow 2(\mathrm{IV}-\mathrm{V})$ & $5 \cdot 1-8 \cdot 1$ & $1 \cdot 1-8 \cdot 3$ \\
\hline $1 \rightarrow 3($ VI-VII $)$ & $1 \cdot 1-1 \cdot 4$ & $13 \cdot 6-19 \cdot 6$ \\
\hline $1 \rightarrow 4$ (VIII-XII) & $0 \cdot 2-2 \cdot 1$ & $0 \cdot 6-7 \cdot 0$ \\
\hline
\end{tabular}

\section{Disaccharides consisting of an aldohexose and an aldopentose}

In the mass spectra of XIX to XXI (Table 1) the molecular ion at m/e 816 was present. Remarkably, also a $(\mathrm{M}-1)^{+}$ion was detectable. Other important ions in the high mass range were $m / e 801\left(\mathrm{M}^{+}-{ }^{-} \mathrm{CH}_{3}\right), m / e 726\left(\mathrm{M}^{\dagger}-\mathrm{TMSOH}\right), m / e 711$ $\left(\mathrm{M}^{ \pm}+{ }^{\cdot} \mathrm{CH}_{3}-\mathrm{TMSOH}\right)$ and $m / e 621\left(\mathrm{M}^{+}-{ }^{\circ} \mathrm{CH}_{3}-2 \mathrm{x}\right.$ TMSOH$)$. Comparison with the mass spectra of aldohexosyl-aldohexoses shows that the fragmentation patterns are practically identical; as a matter of fact fragments now containing an aldopentose unit are shifted to 102 mass units lower. The shifts of ions, which are derived predominantly from either the reducing or the non-reducing site of the molecule, can be used to establish the monosaccharide sequence.

TABLE 5. Relative INTENSITIES OF PAIRS OF PEAKS, APPLICABLE FOR THE SEQUENCE DETERMINATION IN DISACCHARIDES CONTAINING ONE ALDOHEXOSE AND ONE ALDOPENTUSE UNIT. THE PEAKS OF EACH PAIR DIFFER 102 MASS UNITS

\begin{tabular}{|c|c|c|c|}
\hline$m / e$ & $\beta-D-G p-(1 \rightarrow 2)-L-A r a$ & B-D-Galp-(1 $\rightarrow 3)$-D-Ara & B-D-Xylp-(1 $\rightarrow$ 6)-D-G \\
\hline 259 & $10.7 \%(\mathrm{R})$ & $17 \cdot 3 \%(\mathbf{R})$ & $35 \cdot 3 \%$ (NR) \\
\hline 361 & $100 \%$ (NR) & $100 \%$ (NR) & $10.7 \%(\mathbf{R})$ \\
\hline 349 & $5.8 \%(\mathbf{R})$ & $4 \cdot 6 \%(R)$ & $41.9 \%$ (NR) \\
\hline 451 & $15.3 \%$ (NR) & $24.0 \%$ (NR) & $9.3 \%(\mathbf{R})$ \\
\hline $467^{a}$ & $36.5 \%(\mathbf{R})$ & $35 \cdot 2 \%(\mathrm{R})$ & $2 \cdot 2 \%(\mathrm{NR})$ \\
\hline 569 & $0.6 \%(\mathrm{NR})$ & $2.9 \%$ (NR) & $9 \cdot 4 \%(R)$ \\
\hline 581 & $1.8 \%(R)$ & $3 \cdot 3 \%(R)$ & $0 \%(N R)$ \\
\hline 683 & $0.2 \%(\mathrm{NR})$ & $0 \cdot 3 \%(\mathrm{NR})$ & $0-3 \%(R)$ \\
\hline 481 & & & $100 \%(N R)$ \\
\hline 583 & & & $0 \%(R)$ \\
\hline
\end{tabular}

$R=$ reducing end $\quad$ NR $=$ non-reducing end

- In Table 2 still another explanation for this fragment is given 
In the mass spectrum of $\beta-D-X y l p-(1 \rightarrow 6)-D-G(X X I)$ a strong peak is present at $m / e 481$, which is the analogue of $m / e 583$ in aldohexosyl-aldohexoses. This observation makes clear that $\mathbf{m} / \mathrm{e} 583$ originates from the non-reducing end. By consequence the fragment at $m / e 481$ in XXI is indicative of the sequence of monomers and also characteristic for the $(1 \rightarrow 6)$ linkage in aldopentosyl- $(1 \rightarrow 6)$-aldohexoses. The rather high intensity of the ion at $m / e 569$, which stems from the reducing site, in comparison to that of $m / e \mathbf{4 6 7}$ is likewise characteristic for the sequence.

When the aldopentose unit forms the reducing site of the molecule, as is the case in B-D-Gp-(1 $\rightarrow 2)$-L-Ara (XIX) and B-D-Galp-(1 $\rightarrow 3)$-D-Ara (XX), the intensity of the fragment at $m / e 467$ is much higher than that of the ion at $m / e 569$. In a similar way several other ions (Table 5) can be used for sequence determinations.

To distinguish the $(1 \rightarrow 2)$ from the $(1 \rightarrow 3)$ glycosidic link in aldohexosyl-aldopentoses the ratio of the intensities of the ions at $m / e 467$ and $m / e 539$ can be used (comparable with $569 / 539$ in aldohexosyl-aodohexoses). For the $(1 \rightarrow 2)$ and $(1 \rightarrow 3)$ links the ratios amount to $15 \cdot 3$ and $2 \cdot 2$ respectively. For aldohexosyl-aldopentoses the analogue of the ratio 569/668 in aldohexosyl-aldohexoses should be $467 / 566$. By the absence of the fragment at $\mathrm{m} / \mathrm{e} 566$, this ratio could not be established. As no $(1 \rightarrow 4)$ model compound was available, no alternative criteria can be given which are characteristic for this type of bonding. It is noteworthy that the fragment ion at

Table 6. Partial mass SPectra of Some TMS-Trisaccharides $(m / e) 361=100 \%)$

\begin{tabular}{|c|c|c|c|c|}
\hline$m / e$ & XXII & XXIII & XXIV & $X X V$ \\
\hline 1296 & 0.2 & 0.1 & $0-1$ & 0.2 \\
\hline 1281 & 0.1 & 0.2 & 0.2 & 0.2 \\
\hline 1206 & 0.1 & 0.1 & 0.2 & 0.2 \\
\hline 1191 & 0.2 & 0.5 & $0-6$ & 0.7 \\
\hline 1061 & 0.2 & $0-4$ & 0.1 & 0.2 \\
\hline 1046 & 0.7 & 0.2 & - & 0.7 \\
\hline 961 & $0-2^{4}$ & $0.1^{\circ}$ & $1 \cdot 3$ & $0.7^{\circ}$ \\
\hline 960 & 0.3 & 0.2 & 0.6 & 0.7 \\
\hline 956 & $0 \cdot 1$ & - & - & 0.7 \\
\hline 947 & 0.8 & 0.6 & $10-6$ & 7.4 \\
\hline 917 & 1.2 & 1.2 & 0.4 & $2 \cdot 2$ \\
\hline 829 & 1.5 & 1.0 & $2 \cdot 8$ & $1 \cdot 1$ \\
\hline 813 & 0.5 & 0.5 & $1 \cdot 1$ & $1 \cdot 1$ \\
\hline 739 & $0-8$ & $1 \cdot 1$ & $2 \cdot 4$ & $1 \cdot 1$ \\
\hline 683 & 0.5 & $0-5$ & 0.4 & 0.7 \\
\hline 668 & 0.2 & 0.2 & - & 0.3 \\
\hline 583 & $0.6^{b}$ & $0.7^{b}$ & $10-6$ & 2.6 \\
\hline 582 & $0-8$ & $1 \cdot 3$ & 0.5 & 0.7 \\
\hline 578 & $0-2$ & $0 \cdot 3$ & - & 0.4 \\
\hline 569 & 2.6 & 3.6 & $8 \cdot 3$ & $2 \cdot 7$ \\
\hline 539 & 1.9 & 5.9 & 1.5 & 20 \\
\hline 451 & $10-8$ & $11 \cdot 0$ & $26 \cdot 4$ & $15 \cdot 1$ \\
\hline 435 & 1.7 & 2.4 & 4.0 & 2.5 \\
\hline 361 & 100 & 100 & 100 & 100 \\
\hline
\end{tabular}

- isotope peak of $m / e 960$

- isotope peak of $m / e 582$ 
$m / e \mathbf{4 6 7}$ in the aldohexosyl-arabinoses is formed via two routes. For the greater part, this ion is the analogue of $\mathrm{m} / \mathrm{e} 569$ and for a minor part it is identical to the fragment presented in Tablc 2.

\section{Trisaccharides consisting of aldohexoses}

Mass spectra were recorded of TMS ethers of the trisaccharides XXII to XXV (Table 1). The fragment ions are directly comparable with those formed in TMSaldohexosyl-aldohexoses. The ions containing the extra hexosyl unit are found 378 mass units higher than in the disaccharides. In Table 6 a series of the most important fragment ions is given.

For the assignment of the two $(1 \rightarrow 6)$ links in $\alpha-D-G p-(1 \rightarrow 6)-\alpha-D-G p-(1 \rightarrow 6)-D-G$ (XXIV) the same fragment ion as in disaccharides viz. $\mathrm{m} / \mathrm{e} 583$ and its equivalent 378 mass units higher at $m / e 961$ can be used. The intense peak at $m / e 583$ in a trisaccharide is typical for the $(1 \rightarrow 6)$ link between the non-reducing unit and the middle sugar unit, and the intense peak at $m / e 961$ for the $(1 \rightarrow 6)$ link between the middle sugar unit and the reducing unit. In $\alpha-\mathrm{D}-\mathrm{G} p-(1 \rightarrow 6)-\alpha-\mathrm{D}-\mathrm{G} p-(1 \rightarrow 4)-\mathrm{D}-\mathrm{G} p(\mathrm{XXV})$ the $(1 \rightarrow 6)$ link is characterized by a strong peak at $m / e 583$.

It is probable that the $(1 \rightarrow 4)$ links in panose $(\mathrm{XXV})$, maltotriose (XXII) and cellotriose (XXIII) can be assigned on the basis of similar ratios of peak-intensities as described for aldohexosyl-aldohexoses. By the lack of model compounds containing $(1 \rightarrow 2)$ and $(1 \rightarrow 3)$ linkages it would be premature to indicate these ratios.

\section{DISCUSSION}

It was found that the most characteristic differences in the mass spectra of disaccharides built up from units of equal molecular weight arise from variations in the position of the glycosidic link. In some cases these differences are rather small. so that careful recording of the spectra under standard conditions is advisable.

In the following, a further comment is given on the fragment ions which are used for the assignment of the glycosidic linkage.

$1 \rightarrow 1$ linkage. The mass spectra of the non-reducing disaccharides are unique by the presence of the peaks at $m / e 565, m / e 553$ and $m / e 540$. Exact mass measurements revealed the following brutoformulae: $m / e \quad 565=\mathrm{C}_{23} \mathrm{H}_{53} \mathrm{O}_{6} \mathrm{Si}_{5}, m / e \quad 553=$ $\mathrm{C}_{22} \mathrm{H}_{53} \mathrm{O}_{6} \mathrm{Si}_{5}$ and $m / e 540=\mathrm{C}_{21} \mathrm{H}_{52} \mathrm{O}_{6} \mathrm{Si}_{5}$. The fragment ion at $m / e 540$ may be formed as indicated in Fig. 7.

$1 \rightarrow 5$ and $1 \rightarrow 6$ linkages. It is remarkable that in aldohexosyl-aldohexoses a $(1 \rightarrow 5)$ link could not be distinguished from a $(1 \rightarrow 6)$ link, as the ring size of the
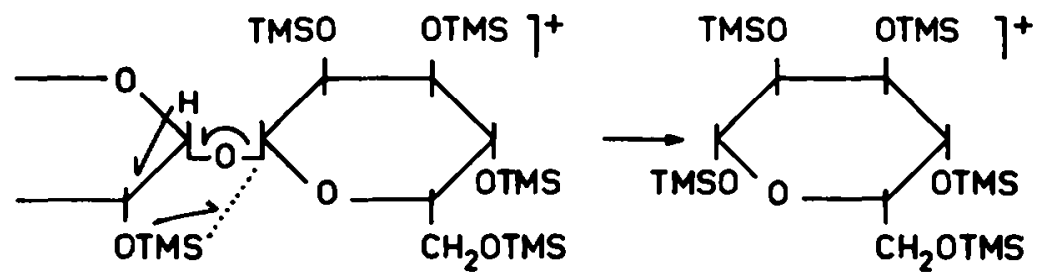

$$
\mathrm{m} / \mathrm{e} 540
$$

Fig 7. Formation of $m / e 540$ in $(1 \rightarrow 1)$ disaccharides 
reducing unit may be different for these components; in the $(1 \rightarrow 5)$ compound it must be a furanose ring and in the $(1 \rightarrow 6)$ compound very likely a pyranose ring (Kochetkov et al..$^{3}$ ). Because in TMS-monosaccharides the intensity of the peak at $m / e 217$ is smaller than that of $m / e 204$ for pyranose forms, whereas the reverse holds for the furanose forms (DeJongh et al. ${ }^{13}$ and Petersson et al. ${ }^{14}$ ), it was obvious to look for the intensity of these peaks in disaccharides. In all reducing aldohexosylaldohexoses including the $(1 \rightarrow 5)$ and $(1 \rightarrow 6)$ bonded components as well as for the trisaccharides, the intensity of the peak at $\mathrm{m} / \mathrm{e} 217$ was smaller than that of the peak at $m / e$ 204. Only in the non-reducing $(1 \rightarrow 1)$ disaccharides was the intensity of $m / e 217$ greater than that of $m / e$ 204. Evidently, the intensity of these peaks can not be used to differentiate between furanose and pyranose ring forms in aldohexosyl oligosaccharides. Although the fragments at $\mathrm{m} / \mathrm{e} 217$ and $\mathrm{m} / \mathrm{e} 204 \mathrm{must}$ arise from the constituting monosaccharides, it is clear that the type of glycosidic link has also a distinct influence on the formation of these ions.

In accordance with the explanation for $m / e 583$ in $(1 \rightarrow 6)$ disaccharides, offered by Kochetkov et al.. ${ }^{3}$ this peak is shifted to $m / e 481$ in $\beta-D-X y l p-(1 \rightarrow 6)-D-G(X X I)$. However. their conclusion that the intense peak at $m / e 583$ is typical of $(1 \rightarrow 6)$ linkages has to be modified, as it is also present in $(1 \rightarrow 5)$ disaccharides. In the latter case the fragment at $m / e .583$ arises from cleavage of the bond between $\mathrm{C}_{4}$ and $\mathrm{C}_{5}$ in the reducing moiety. Surprisingly, in the mass spectra of the three non-reducing disaccharides of the trehalose type the fragment at $\mathrm{m} / \mathrm{e} 583$ was also present, albeit in a very low abundance. Exact mass measurements revealed that its brutoformula $\mathrm{C}_{23} \mathrm{H}_{55} \mathrm{O}_{7} \mathrm{Si}_{5}$ was identical to that of $m / e 583$ in $(1 \rightarrow 5)$ and $(1 \rightarrow 6)$ bonded components. For the peak at $m / e 583$ in $(1 \rightarrow 1)$ disaccharides a structure is given in Fig 8.

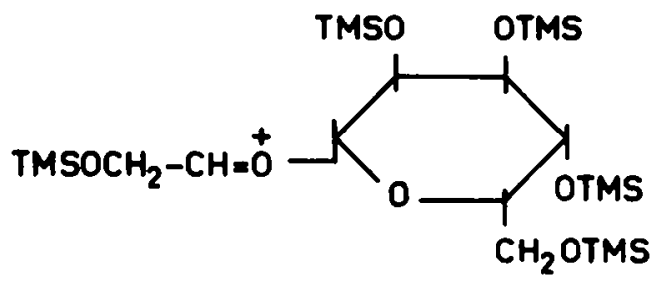

$\mathrm{m} / \mathrm{e} 583$

FiG 8 . Structure of $m / e 583$ in $(1 \rightarrow 1)$ disaccharides

$1 \rightarrow 2,1 \rightarrow 3$ and $1 \rightarrow 4$ linkages. The differentiation between the $(1 \rightarrow 2),(1 \rightarrow 3)$ and $(1 \rightarrow 4)$ aldohexosyl-aldohexoses is rather subtle. Kochetkov et al. ${ }^{3}$ postulated that this group of components is characterized by a common peak at $m / e$ 683. The $(1 \rightarrow 2)$ and $(1 \rightarrow 4)$ linked have furthermore a relatively intense peak at $m / e 668$. whereas they differ in the intensities of the peak at $m / e 569$. However, in the present study it was found that $m / e \quad 683$ was also observable in most of the spectra of $(1 \rightarrow 5)$ and $(1 \rightarrow 6)$ linked disaccharides and the peaks at $\mathrm{m} / \mathrm{e} 668$ and $\mathrm{m} / \mathrm{e} 578$ were also detectable in the spectra of the $(1 \rightarrow 3)$ linked aldohexosyl-aldohexoses, although their intensities were rather low. Furthermore, the relative intensity of the fragment at $m / e 569$ varied strongly with the type of the constituent monosaccharides (Vink 
et $\left.a l . .^{9}\right)$ and to a smaller extent with the configuration of the glycosidic link. On the basis of these observations preference was given to the use of ratios of peak intensities over the utilization of rclative peak intensities expressed as a percentage of a base peak or of a sum of peaks. The latter data are not characteristic enough.

$m / e$ 683. From our results it can be concluded that the peak at $m / e \quad 683$ in aldohexosyl-aldohexoses originates mainly from the reducing site of the molecule. because the peak is present in the spectrum of the xylosyl-glucose while it has for the greater part been shifted to $\mathrm{m} / \mathrm{e} 581$ in the aldohexosyl-arabinoses. Therefore the assumption of Kochetkov et al. $^{3}$ that the fragment at $m / e 683$ stems from the non-reducing site holds true only for a small part of the intensity of this peak (Tables 2 and 5).

$m / e$ 668. The brutoformula of the fragment at $m / e 668$ (in $(1 \rightarrow 2)$ disaccharides) was established by exact mass measurement to be $\mathrm{C}_{27} \mathrm{H}_{64} \mathrm{O}_{7} \mathrm{Si}_{6}$ (Table 2). By consequence, this ion can not be formed by the elimination of ${ }^{\circ} \mathrm{CH}_{3}$ from $m / e 683$ $\left(\mathrm{C}_{27} \mathrm{H}_{63} \mathrm{O}_{8} \mathrm{Si}_{6}\right)$ as suggested by Chizhov et al. ${ }^{2}$ However, the latter explanation can be correct for the very low peak at $m / e 668$ in $(1 \rightarrow 1)$ disaccharides because in this case the brutoformula turned out to be $\mathrm{C}_{26} \mathrm{H}_{60} \mathrm{O}_{8} \mathrm{Si}_{6}$.

$m / e 569$. Besides the way of formation of $m / e 569$ as proposed by Kochetkov et al. ${ }^{3}$ (Table 2) another route exists, because a small peak at $m / e 569$ was present in the aldohexosyl-arabinoses. A structure for this fragment is given in Fig 9. In some of the non-reducing disaccharides the fragment at $m / e 569$ is also observable, albeit in very low abundance.

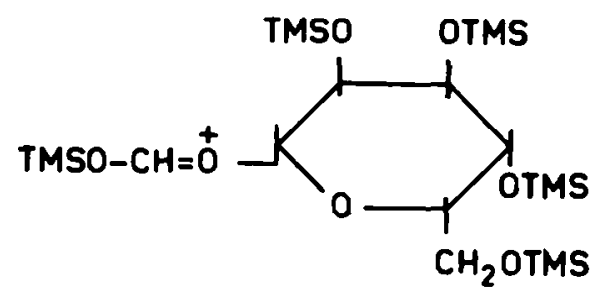

$\mathrm{m} / \mathrm{e} 569$

FIG 9. Structure of $m / e 569$ resulting from the non-reducing site of the molecule

$m / e$ 539. In the literature no explanation has been presented for the fragment ion at $m / e 539$ (c.f. Kärkkäinen ${ }^{4}$ ). By exact mass measurements the brutoformula was found to be $\mathrm{C}_{21} \mathrm{H}_{51} \mathrm{O}_{6} \mathrm{Si}_{5}$, corresponding to TMS-aldohexose minus $1 \mathrm{H}$. A structure for this fragment is given in Fig 10. From the spectra of disaccharides containing

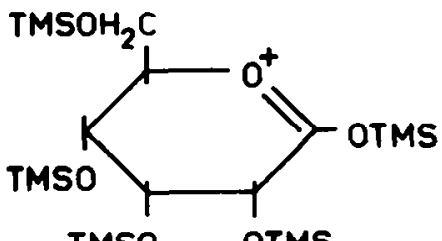

TMSO

OTMS

$\mathrm{m} / \mathrm{e} 539$

Fig 10 . Structure of $m / e s 39$ 
an aldopentose unit it can be deduced that this ion originates for the greater part from the non-reducing unit.

The spectra of all TMS-aldohexosyl-aldohexoses have some important peaks in common, which need further explanation. The formation of the fragment ions at $\mathrm{m} / \mathrm{e} 525, \mathrm{~m} / \mathrm{e} 435$, and $\mathrm{m} / \mathrm{e} 393 \mathrm{can}$ be explained starting from the intermediate presented in Fig. 11. The presence of $m / e 540$ in the non-reducing disaccharides (Fig. 7) supports this proposal. For the formation of the fragment at $m / e 451$ three routes are available: direct cleavage of the bond on the right or the left side of the $\mathrm{O}$-atom of the glycosidic
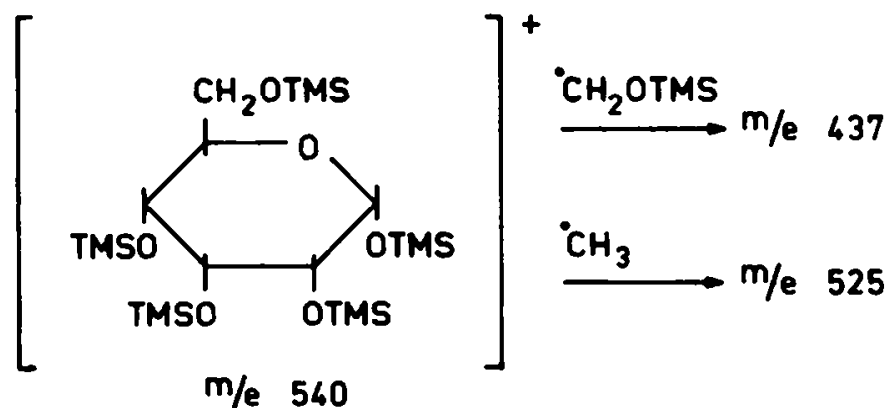

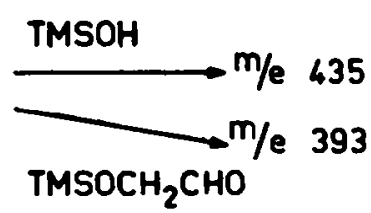

FiG 11. Formation of some fragment ions from $m / e ~ s 40$

linkage, or degradation of the fragment ion at $m / e 569$ (metastable peak at $\mathrm{m}^{*}=$ 358.5). As is evident from Table 5 the ion at $m / e 451$ in an aldohexosyl-aldohexose is for the greater part formed by the direct cleavage of the bond between the anomeric $\mathrm{C}$-atom of the non-reducing moiety and the glycosidic oxygen. The peak at $m / e 361$ arises by the elimination of TMSOH from $m / e$ 451. Besides the criteria for the determination of the monosaccharide sequence in aldopentose containing disaccharides mentioned in Table 5, a more generally applicable parameter was found to be the sum of the intensities of the related fragments $m / e 451$ and $m / e 361$. This can also be illustrated by the mass spectra of the 2-acetamido-2-deoxy-D-glycose containing oligosaccharides (to be published) and by the mass spectra of $\alpha-\mathrm{L}-\mathrm{Ara}-(1 \rightarrow 6)-\mathrm{D}-\mathrm{G}(\mathrm{m} / \mathrm{e}$ $361+m / e 451<m / e 259+m / e 349)$ and $\alpha-\mathrm{L}-\mathrm{Rha-}(1 \rightarrow 6)-\mathrm{D}-\mathrm{G}(m / e 361+m / e$ $451<m / e 273+m / e 363$ ) published by Kochetkov et al. ${ }^{3}$

This study has shown the applicability of mass spectrometry for the determination of the position of the glycosidic bond in lower oligosaccharides. In oligosaccharides consisting of units which differ in molecular weight, determination of the monosaccharide sequence is possible.

\section{EXPERIMENTAL}

The trimethylsilyl derivatives were synthesized as follows. An oligosaccharide $(0.5 \mathrm{mg})$ was dissolved in pyridine $(1 \mathrm{ml})$. Subsequently hexamethyldisilazane (HMDS) $(0-2 \mathrm{ml})$ and trimethylchlorosilane (TMCS) $(0.1 \mathrm{~m})$ were added. After two hr at room temperature (disaccharides) and $3 \mathrm{hr}$ at $70^{\circ}$ (higher oligosaccharides) hexane $(2 \mathrm{ml})$ and water $(2 \mathrm{ml})$ were added to the turbid mixture. The two layer system was strongly agitated and the water layer was removed. The hexane layer was washed with water (1 ml), dried over anhyd $\mathrm{Na}_{2} \mathrm{SO}_{4}$ and evaporated in vacuo. The residue was dissolved in hexane ( $\mathrm{ml}$ ). When the oligosaccharide did not dissolve easily in pyridine, a very small drop of water was added before the addition of pyridine. In this case $0.6 \mathrm{ml}$ of HMDS and $0.3 \mathrm{ml}$ of TMCS was used. Reducing oligosaccharides were anomerized in water ( $48 \mathrm{hr}$, room temperature). $10 \mu$ of this solution was used for mass spectrometry. 
Carbohydrates were either commercially available (J. T. Baker Chemicals N.V.. Pierce Chemical Company and EGA-Chemie KG) or were gifts from various investigators (acknowledgements).

The $70 \mathrm{eV}$-mass spectra were recorded on an AEI MS9 mass spectrometer at an ion chamber temperature of $80-100^{\circ}$ for the disaccharides and $120-140^{\circ}$ for the trisaccharides.

Acknowledgements-For valuable gifts of samples we are indebted to Prof. Dr G. O. Aspinall (mannobiose). Dr G. G. Birch ( $\beta, \beta$-trehalose and $\alpha, \alpha$-galactotrehalose), Dr A. Cepure (3-O- $\beta$-D-Galp-D-Ara), Dr G. Ekborg (2-O- $\beta$-D-Gp-L-Ara), Dr I. J. Goldstein (laminaribiose), Dr P. A. J. Gorin (6-O- $\alpha$-D-Manp-D-G). Dr B. H. Koeppen (sophorose and kojibiose), Dr G. Maghuin-Rogister (maniocose), Dr A. J. Michell (cellotriose), Prof. Dr J. Montreuil (3-O- $\alpha-M a n p-D-M a n)$. Dr N. K. Richtmyer (neolactose and primeverose) and Prof Dr M. Stephen (6-O- $\alpha$-D-Galp-D-Gal). This investigation was supported by the Netherlands Foundation for Chemical Research (SON) with financial aid from the Netherlands Organization for the Advancement of Pure Research (ZWO).

\section{REFERENCES}

O. S. Chizhov, L. A. Polyakova and N. K. Kochetkov, Dokly Akad. Nauk SSSR 158. 685 (1964)

O. S. Chizhov, N. V. Molodtsov and N. K. Kochetkov, Carbohyd. Res. 4.273 (1967)

3 N. K. Kochetkov, O. S. Chizhov and N. V. Molodtsov, Tetrahedron 24, 5587 (1968)

4 J. Kärktäinen, Carbohyd. Res. 11, 247 (1969)

5 Idem. Ibid. 14, 27 (1970)

6 G. S. Johnson. W. S. Ruliffson and R. G. Cooks. Chem. Comm. 587 (1970)

7 J. Kărkkäinen, Carbohyd. Res. 17. 1 (1971)

8 Idem., Ibid. 17. 11 (1971)

9 J. Vink, J. J. de Ridder. J. P. Kamerling and J. F. G. Vliegenthart, Biochem. Biophys. Res. Comm. 42. 1050 (1971)

10 J. Haverkamp. J. P. Kamerling and J. F. G. Vliegenthart. J. Chromatog. 99,281 (1971)

11 T. Bhatti, R. E. Chambers and J. R. Clamp. Biochim. Biophys. Acta 222, 339 (1970)

12 J. P. Kamerling. D. Rosenberg and J. F. G. Vliegenthart, Biochem. Biophys. Res. Comm. 38.794 (1970)

13 D. C. DeJongh. T. Radford, J. D. Hribar. S. Hanessian. M. Bieber. G. Dawson and C. C. Sweeley. J. Am. Chem. Soc. 91,1728 (1969)

14 G. Petersson and O. Samuelson. Svensk Papperstidn. 71, 731 (1968) 